\title{
Measurement of the Risk for Substance Use Disorders: Phenotypic and Genetic Analysis of an Index of Common Liability
}

Michael M. Vanyukov $\cdot$ Levent Kirisci $\cdot$ Lisa Moss $\cdot$

Ralph E. Tarter · Maureen D. Reynolds · Brion S. Maher •

Galina P. Kirillova $\cdot$ Ty Ridenour $\cdot$ Duncan B. Clark

Published online: 2 August 2009

(C) Springer Science+Business Media, LLC 2009

Erratum to: Behav Genet (2009) 39:233-244

DOI 10.1007/s10519-009-9269-9

On p. 241, left column, line 3 from the top, it should read "higher" (onset age) instead of "lower".
Corrected text should read

.... the disorder is more likely to have already developed in individuals with higher liability, whereas those with lower liability (one of the manifestations of which is a higher onset age) have not yet realized their risk.

The online version of the original article can be found under doi: 10.1007/s10519-009-9269-9.

M. M. Vanyukov $(\bowtie) \cdot$ L. Kirisci $\cdot$ R. E. Tarter

M. D. Reynolds · G. P. Kirillova - T. Ridenour · D. B. Clark

Center for Education and Drug Abuse Research (CEDAR),

Department of Pharmaceutical Sciences, School of Pharmacy,

University of Pittsburgh, 711 Salk Hall, Pittsburgh, PA 15261,

USA

e-mail: mmv@pitt.edu

M. M. Vanyukov · L. Kirisci - R. E. Tarter · D. B. Clark

Department of Psychiatry, University of Pittsburgh Medical

School, Pittsburgh, PA 15213, USA

M. M. Vanyukov · L. Moss

Department of Human Genetics, University of Pittsburgh School

of Public Health, Pittsburgh, PA 15261, USA

B. S. Maher

Virginia Institute for Psychiatric and Behavioral Genetics, Virginia Commonwealth University, Richmond, VA 23219,

USA

Present Address:

L. Moss

Department of Ob/Gyn, University of New Mexico,

Albuquerque, NM 87131, USA 